\title{
CARACTERIZAÇÃO ESTRUTURAL DO MANGUEZAL DO RIO TABATINGA, SUAPE,
} PERNAMBUCO, BRASIL

\author{
V. C. ALMEIDA ${ }^{1}$ \\ C. COELHO JUNIOR ${ }^{2}$ \\ F. FEITOSA. ${ }^{3}$ \\ D. PASTOR ${ }^{4}$ \\ G. MONTE 5
}

Recebido em: 05/02/2014

Aceito em: 26/02/2014

\section{RESUMO}

Manguezal, ecossistema costeiro tropical que coloniza depósitos sedimentares formados por vasas lamosas, argilosas ou arenosas, ocupando a faixa do entremarés até 0 limite superior das preamares equinociais. O Complexo Industrial Portuário de Suape localiza-se no litoral sul do Estado de Pernambuco. Caracteriza-se por ser um ambiente costeiro, formado por extensos manguezais. A presente análise teve como objetivo descrever as características estruturais do bosque de mangue do rio Tabatinga. A caracterização estrutural mostrou que o bosque analisado é maduro e que apresenta um bom desenvolvimento estrutural, variando em área basal total de $11,17 \mathrm{~m}^{2} /$ ha a $42,35 \mathrm{~m}^{2} /$ ha e altura média de 8,55 a $3,57 \mathrm{~m}$. O bosque é monoespecífico, dominado por Laguncularia racemosa. As análises de troncos mortos revelam que apesar da área ser desenvolvida, existe sinal de stress por ação antrópica. A salinidade variou entre 12 a 42. A metodologia utilizada mostrou-se adequada como ferramenta para avaliar a estrutura de bosques de mangue.

Palavras-chave: Desenvolvimento estrutural, Manguezal, Suape.

\section{ABSTRACT}

Mangroves, tropical coastal ecosystem that colonizes sedimentary deposits formed by vasas lamosas, clayey or sandy, occupying the bounderies of entremares until the upper limit of the equinoctial high tide. The Suape Port and Industrial Complex is located on the south coast of the State of Pernambuco. The region is placed as a coastal environment, formed by extensive mangroves The objective of this analysis is to describe the structural characteristics of Tabatinga river's mangrove swamp. The structural study showed that the shrubland analyzed was mature and presented a solid structural development, varying in total base area from $11,17 \mathrm{~m}^{2} / \mathrm{ha}$ to $42,35 \mathrm{~m}^{2} / \mathrm{ha}$ and in average height from 8,55 to $3,57 \mathrm{~m}$. The mangrove forest is mono-specific, dominated by Laguncularia racemosa. Analysis of dead trunks revealed that although the area is developed, there exists a sign of stress due to anthropic action. The salinity varied between 12 and 42 . The methodology used proved adequate as a means to analyze the structure of the mangrove forest.

Keywords: Structural Development, mangroves, CIPS

\section{INTRODUÇÃO}

Manguezal, ecossistema costeiro tropical que coloniza depósitos sedimentares formados por vasas lamosas, argilosas ou arenosas, ocupando a faixa do entremarés até o limite superior das preamares equinociais. Apresenta distribuição descontínua ao longo do litoral brasileiro, do Amapá a Santa Catarina, podendo apresentar um continuum de feições distintas em função do perfil da linha de costa e das frequências e amplitude das marés (SCHAEFFER-NOVELLI, 2002).

\footnotetext{
1 Universidade Federal de Pernambuco, Departamento de Oceanografia. E-mail: viviane_almeida31@hotmail.com

2 Universidade de Pernambuco, Instituto de Ciências Biológicas. E-mail: clemente.coelhojr@biomabrasil.org

3 Universidade Federal de Pernambuco, Departamento de Oceanografia. E-mail: feitoc01@yahoo.com.br

4 Universidade de Pernambuco, Instituto de Ciências Biológicas E-mail: danilo.pastor@outlook.com

5 Universidade de Pernambuco, Instituto de Ciências Biológicas. E-mail: gugu_espider25@hotmail.com
} 
ALMEIDA, V. C. et al. Caracterização estrutural do manguezal do rio Tabatinga, Suape, Pernambuco, Brasil.

As condições ideais de temperatura e precipitação para um melhor desenvolvimento do ecossistema manguezal são: temperaturas médias acima de $20^{\circ} \mathrm{C}$, com amplitude térmica anual menor que $5^{\circ} \mathrm{C}$ e precipitação pluvial acima de $1.500 \mathrm{~mm} /$ ano, sem prolongados períodos de chuva (SCHAEFFER-NOVELLI, 1995). Portanto apresentam maior desenvolvimento na faixa entre os trópicos de câncer e capricórnio $\left(23^{\circ} 27^{\prime} \mathrm{N}\right.$ e $\left.23^{\circ} 27^{\prime} \mathrm{S}\right)$, justamente por ser uma formação tropical. (SCHAEFFER-NOVELLI, op cit.).

O ecossistema manguezal encontra-se bem representado ao longo do litoral brasileiro, muitas vezes associado a lagunas, estuários e baías, ou diretamente exposto na linha de costa (SCHAEFFER-NOVELLI et al, 1994). Representa $8 \%$ de toda a linha de costa do planeta e um quarto da linha de costa da zona tropical, perfazendo um total de $181.077 \mathrm{~km} 2$. No mundo há cerca de $162.000 \mathrm{Km}^{2}$ e no Brasil possui uma área estimada de $12.264,43 \mathrm{Km}^{2}$, sendo considerado a segunda maior área do globo (SCHAEFFER-NOVELLI op cit; GIRI et al. 2010; MMA 2010).

O ecossistema manguezal presta vários serviços, dentre eles destacam-se, fonte de detritos para as regiões costeiras adjacentes, constituindo a base de teias tróficas de espécies de importância econômica e/ou ecológica; área de reprodução, abrigo, alimentação e desenvolvimento de espécies marinhas, estuarinas, terrestres e límnicas; manutenção da diversidade biológica da região costeira; proteção da linha de costa, evitando erosão da mesma e assoreamento dos corpos d'água adjacentes; fonte de alimentos e produtos diversos, associados à subsistência de comunidades tradicionais que vivem em áreas vizinhas (SCHAEFFER-NOVELLI, op cit.).

O mecanismo de manutenção dos processos ecossistêmicos são as marés diárias. A distância máxima de penetração da água salgada determina o limite de ocorrência do manguezal em direção a terra firme (SCHAEFFER-NOVELLI, op cit.).

A floresta de mangueem Pernambuco está composta principalmente pelo "mangue vermelho" Rhizophora mangle L. (Rhizophoracea), "mangue siriúba" (Avicennia schauerianae, A. germinans Stapf. e Leechmam (Avicenniaceae), "mangue branco" Laguncularia racemosa (L.) Gaertn. f. (Combretaceae).

A salinidade é um fator importante para distribuição das espécies de mangue. De acordo com Hutchings e Saenger (1987), a salinidade da água intersticial é reconhecida como um importante fator regulador do crescimento, altura, sobrevivência e zonação das espécies de mangue. A tolerância a salinidade é um dos fatores que contribuem para a zonação da vegetação de mangue ao longo do ecossistema. A variação na frequência de inundação das marés pode acarretar diferenças nas concentrações de sal no sedimento, tanto em relação ao mar, quanto em relação à fonte de água doce. Sendo assim as diferentes espécies vegetais de mangue estão distribuídas no manguezal em zonas, em relação à linha d'água. Esta zonação depende da salinidade, das marés, do tipo de substrato e do grau de energia do local (SCHAEFFER-NOVELLI; CINTRÓN, 1986).

Cintrón e Schaeffer-Novelli (1985) afirmam que o desenvolvimento estrutural alcançado por um bosque de mangue é função dos níveis de periodicidade das energias subsidiárias, como da natureza e intensidade dos tensores antrópicos ou naturais presentes. Sua descrição fornece a ideia de desenvolvimento, além de permitir realizar a comparação entre áreas. A descrição desta estrutura inclui medidas de altura, diâmetro, área basal e densidade de árvores (SCHAEFFER-NOVELLI; CITRÓN, 1986).

O objetivo do trabalho foi descrever as características estruturais do bosque de mangue do rio Tabatinga.

\section{MATERIAL E MÉTODOS}

\section{Área de Estudo}

O Complexo Industrial Portuário de Suape (CIPS) localiza-se no litoral sul do Estado de Pernambuco, estendendo-se longitudinalmente à linha de costa, a cerca de $40 \mathrm{~km}$ da cidade do Recife. Possui cerca de $135 \mathrm{~km}^{2}$ de área, abrangendo trechos dos municípios de Cabo de Santo Agostinho e Ipojuca (CAVALCANTI, 2010). 
ALMEIDA, V. C. et al. Caracterização estrutural do manguezal do rio Tabatinga, Suape, Pernambuco, Brasil.

Situa-se na zona fisiográfica compreendida entre os paralelos $8^{\circ} 15^{\prime} 00^{\prime \prime} \mathrm{S}$ e $8^{\circ} 30^{\prime} 00^{\prime \prime} \mathrm{S}$ e os meridianos $34^{\circ} 55^{\prime} 00^{\prime \prime} \mathrm{W}$ e $35^{\circ} 05^{\prime} 00^{\prime \prime} \mathrm{W}$. Apresenta a foz de confluência dos rios Jaboatão e Pirapama no estuário de Barra de Jangadas como limite norte, e o Pontal do Cupe como limite sul. A área é cortada por diversos rios e riachos, com maior concentração ao sul do Cabo de Santo Agostinho. Antes da implantação do porto, em 1979/80, convergiam para a baía de Suape, no sentido norte-sul, os rios Massangana, Tatuoca, Ipojuca e Merepe. Os dois últimos tinham suas águas canalizadas pela extensa linha de arrecifes de arenito, interrompidas ao norte pelo cabo de Santo Agostinho (CAVALCANTI, op cit.).

Quanto a geomorfologia e sedimentologia quaternária de Suape, a área pode ser dividida em três compartimentos: colinas arredondadas, rampas de colúvio e planície costeira, sendo que a última domina toda a parte sudoeste e, quase totalmente, as partes sudeste e nordeste da área. Esta planície é composta por três tipos de ambientes de deposição diferentes: ambientes de depósitos fluviais, de depósitos de mangue e de depósitos marinhos. Dentre estes, os de mangues são os que predominam, cobrindo grande parte da faixa central da área, na direção N-S (CAVALCANTI, op cit.).

Dados hidrológicos obtidos antes da implantação do porto permitiram a classificação do ecossistema em três zonas: (a) marinha costeira, abrangendo a baía de Suape; (b) estuarina com regimes salinos polialinos, compreendendo os rios Massangana e Tatuoca; e (c) estuário do Rio Ipojuca, com regime de salinidade variando de polialino a limnético. Após a implantação do porto, a baía de Suape continua com características marinhas, os rios Massangana e Tatuoca apresentam altas salinidades em suas áreas mais internas, enquanto o Rio Ipojuca continua polialino, porém com variações máximas e mínimas mais acentuadas e com ciclos extremamente irregulares, em consequência da alteração do ritmo das marés (SOUZA $E$ SAMPAIO, 2001).

O clima é tropical úmido do tipo A's, segundo a classificação de Köppen, e, segundo Andrade e Lins (1971), é pseudotropical, com um período seco entre setembro e fevereiro e outro chuvoso de março a agosto.

Na figura 1 está representada a série temporal do fluxo de precipitação durante o período de coleta. A série temporal revela um ciclo anual bem marcado nos anos de 2012 e 2013 com os maiores valores de fluxo de precipitação nos meses de Junho e Julho. O valor médio para o período analisado é de 135,02 $\mathrm{mm}^{3}$. O valor máximo ocorreu no mês de junho de 2013 (338,9 $\left.\mathrm{mm}^{3}\right)$. O valor mínimo foi observado no mês de fevereiro de $2013\left(9,6 \mathrm{~mm}^{3}\right)$.

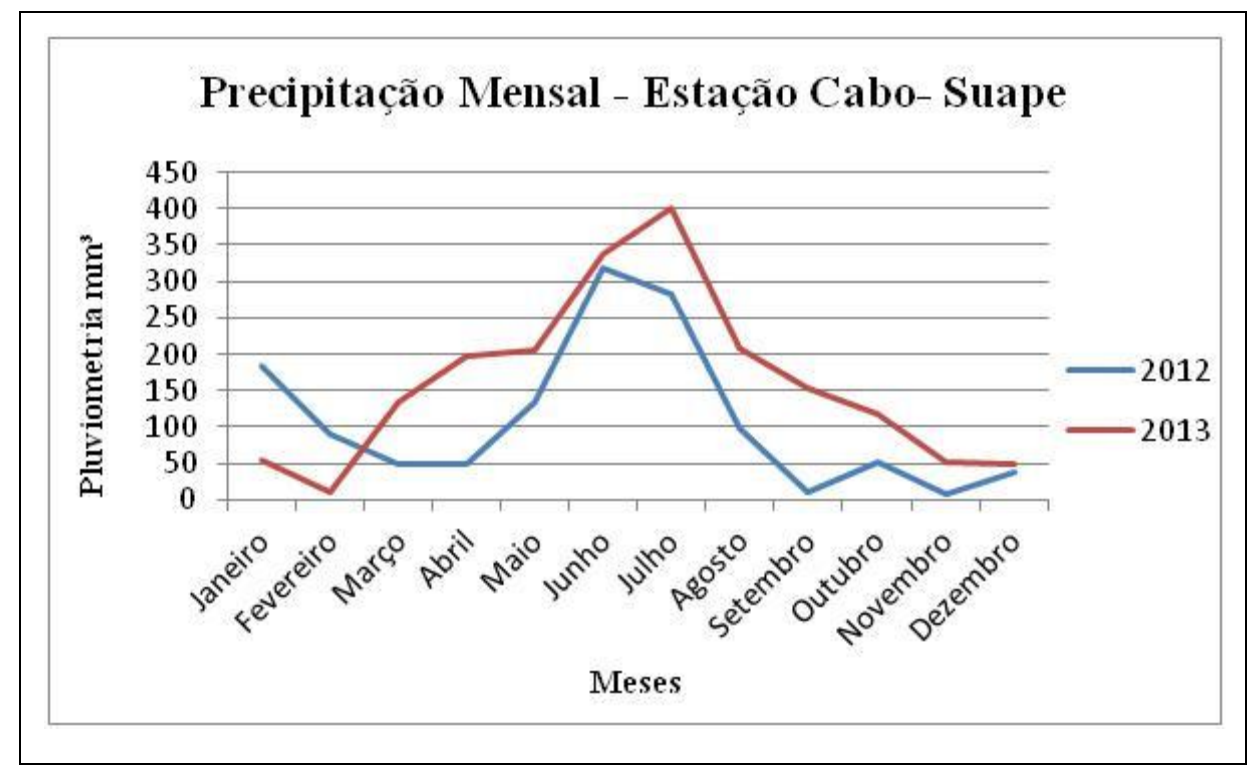

Figura 1 - Série temporal de fluxo de precipitação médio anual da região de Suape - PE. No período de janeiro de 2012 a dezembro de 2013. Dados obtidos na estação meteorológica do cabo. Fonte: APAC. 
ALMEIDA, V. C. et al. Caracterização estrutural do manguezal do rio Tabatinga, Suape, Pernambuco, Brasil.

O rio Tabatinga é um tributário do Massangana, desaguando próximo ao Canal do Diamar, compondo em sua porção baixa o estuário deste último. Nasce no município do Ipojuca, próximo a PE-60, cruzando a TDR-Norte sentido leste-oeste, e compõe os rios que formam a Bacia Hidrográfica do Ipojuca (Figuras 2) (SUAPE, 2010).

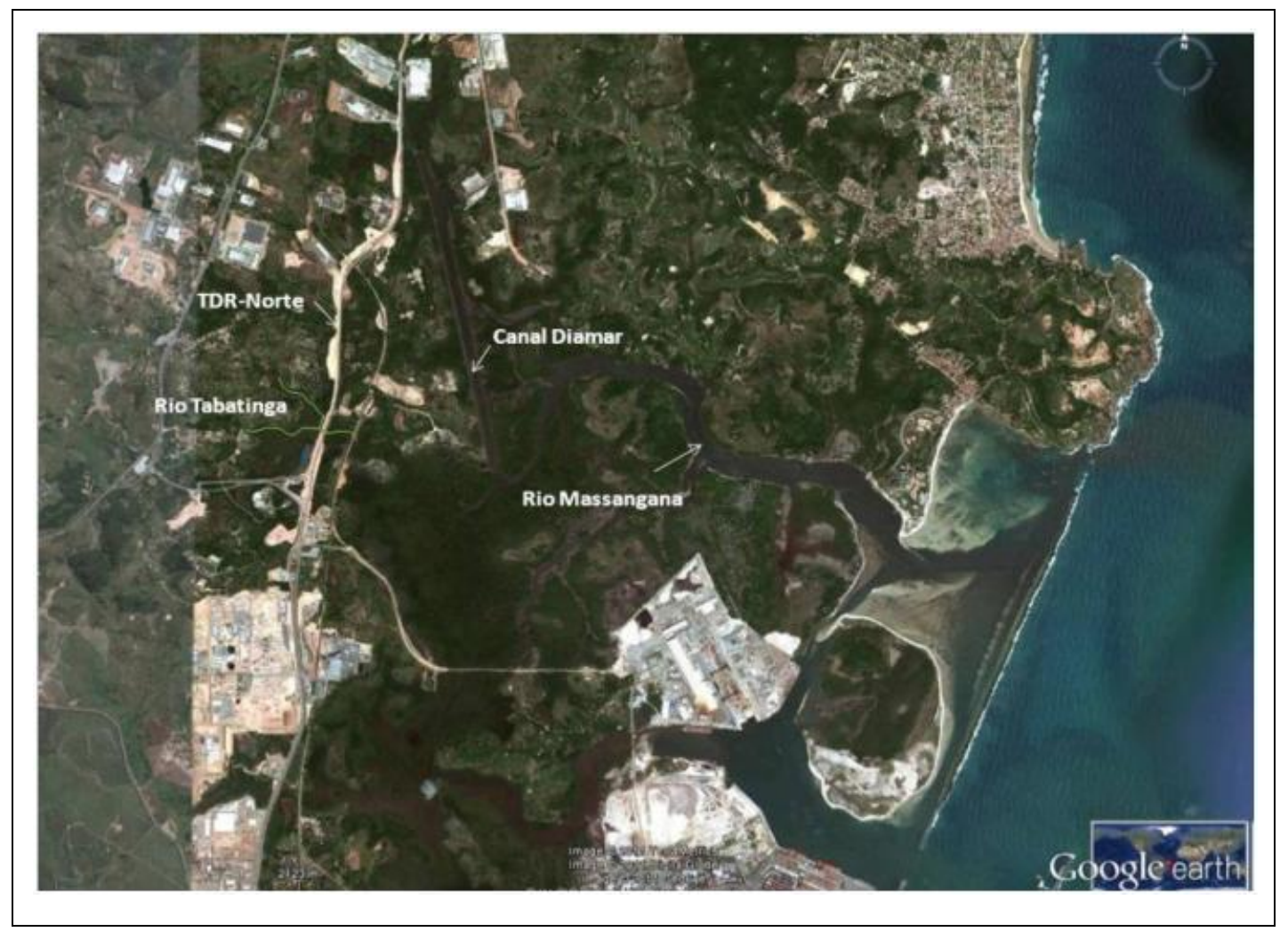

Figura 2 - Localização do rio Tabatinga. Fonte: Goolge Earth.

Os bosques de mangue localizados ao lado direito da rodovia TDR Norte, sentido porto, são dominados pela espécie conhecida como $L$. racemosa. Trata-se de uma espécie comum para os manguezais da região. Segundo o "Estudo Fitossociológico da Área do Estuário do rio Tatuoca", realizado pelo Complexo Industrial Portuário de Governador Eraldo Gueiros - CIPS Suape, é a espécie dominante em boa parte do manguezal do referido rio (SUAPE, 2010). Adaptada às diversas condições do meio podem compor bosques mistos com as outras duas espécies, Rhizophora mangle e Avicennia schaueriana. (Figura 3).

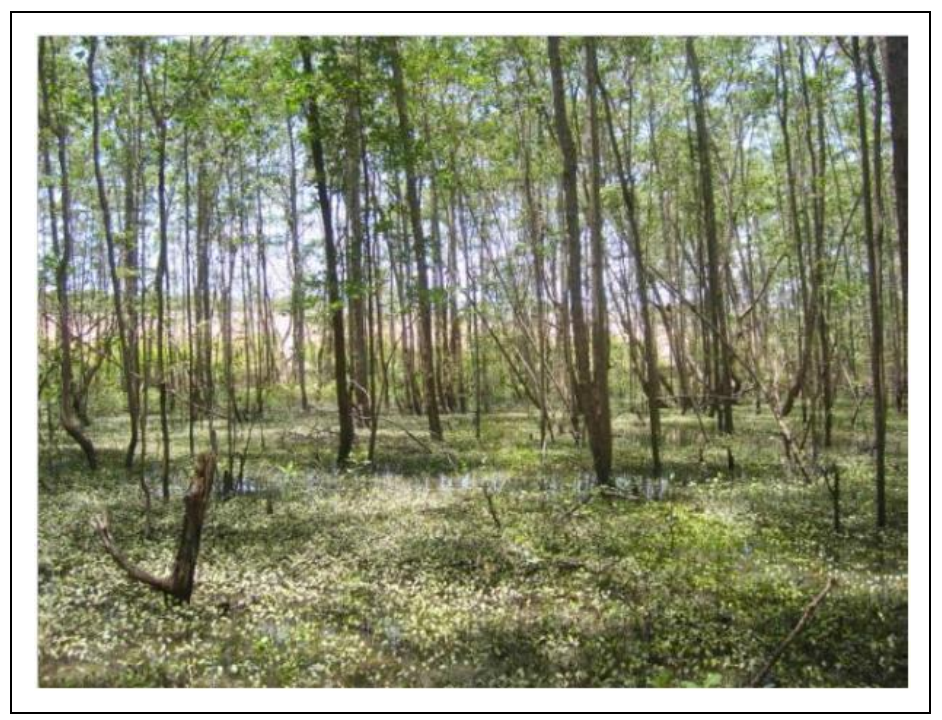

Figura 3 - Manguezal do rio Tabatinga, Suape, Pernambuco. 
ALMEIDA, V. C. et al. Caracterização estrutural do manguezal do rio Tabatinga, Suape, Pernambuco, Brasil.

\section{Atividades de campo}

Os trabalhos de campo foram divididos em 2 etapas: caracterização estrutural e coleta da salinidade intersticial.

\section{Salinidade intersticial do sedimento}

Para a análise de salinidade intersticial foram coletadas 2 amostras de água do sedimento na região central de cada parcela ao longo dos perfis. A água coletada para a leitura foi obtida escavando-se $30 \mathrm{~cm}$ de profundidade com auxílio de um escavador. A água coletada foi lida em um refratômetro óptico (Modelo Instrutherm, escala 0 a 100, \pm 1 UPS). A análise foi realizada em setembro de 2013.

\section{Caracterização estrutural}

Tem-se, há muito tempo, que as medidas estruturais são ótimas indicadoras da qualidade ambiental do ecossistema manguezal. A metodologia estrutural aplicada no presente trabalho é resultado de uma forte discussão científica na década de 80 , sendo confirmada até os dias de hoje como a melhor ferramenta para se conhecer os bosques de mangue. Tal metodologia foi adotada pela UNESCO (Cintrón e Schaeffer-Novelli, 1984) e amplamente difundida no Brasil e no Mundo.

No Brasil, tais medidas auxiliaram na caracterização de diversos manguezais, como os trabalhos de Bernini e Rezende (2004, 2010) no Espírito Santo, Coelho-Jr (1998, 2003), Menghiniet al.(2004, 2008) e Cunha-Lignon (2001, 2005) em São Paulo, Soares (1999, 2003) no Rio de janeiro, Nascimento-Filho (2007), Souza e Sampaio (2001), Medeiros e Sampaio (2009) em Pernambuco, dentre outros.

Neste sentido, utilizou-se a metodologia padrozina da proposta por (Schaeffer-Novellie e Cintron, 1986; Cintrón e Schaeffer-Novelli, 1984).

Foram delimitadas quatro parcelas justapostas ao longo de cinco transectos paralelos (A, $B, C, D$ e E) (Figura 4)com $60 \mathrm{~m}$ cada de extensão, distantes entre si por cerca de $20 \mathrm{~m}$. Os transectos foram traçados transversalmente a rodovia TDR-Norte, sentido manguezal adentro. As parcelas variaram de $10 \times 10$ a $7 \times 7 \mathrm{~m}$, dependendo da densidade de indivíduos. A caracterização estrutural foi realizada entre 2012 e 2013.

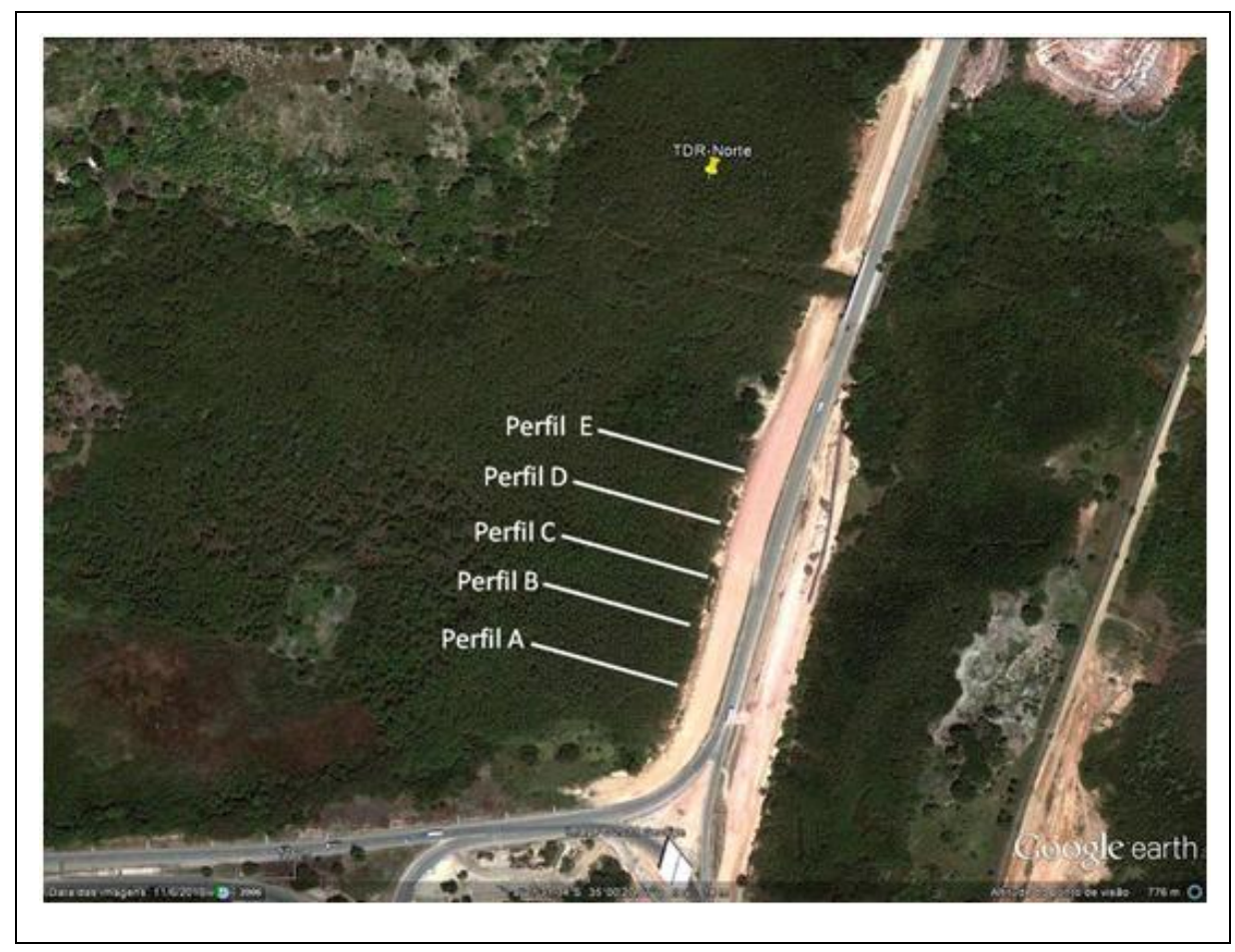

Figura 4 - Imagem da área de estudo com o posicionamento dos transectos perpendiculares a estrada. Fonte: Google Earth. 
ALMEIDA, V. C. et al. Caracterização estrutural do manguezal do rio Tabatinga, Suape, Pernambuco, Brasil.

Iniciou-se a caracterização estrutural com a obtenção de medidas do diâmetro das árvores de mangue dentro da parcela, assumindo que a árvore apresenta secção transversal circular. Para as árvores de maior porte utilizou-se uma trena graduada em unidades de $\Pi(3,14159)$ e para as árvores de menor porte utilizou-se um paquímetro também graduado em unidades de $\Pi(3,14159)$, o que permite uma leitura direta do valor do diâmetro em centímetros. O diâmetro das árvores foi medido à altura do peito do observador (DAP) à 1,3m do solo.

As medidas de altura foram feitas da base da árvore à extremidade superior da copa, com auxilio de telêmetro óptico (Modelo Ranging Opti-Meter 120, de 2 à $30 \mathrm{~m}$ de alcance) e vara telescópica.

\section{Tratamento dos dados estruturais}

As medidas obtidas em campo são registradas em fichas e posteriormente transferidas para planilha Excel para tratamento dos dados estruturais. As medidas de diâmetro são organizadas em planilhas por classe: menor $<2,5, \geq 2,5 e \geq 10$, para o cálculo de área basal total (viva mais morta). Calculou-se a média aritmética e altura média do dossel, considerando as três mais altas. Foram calculados ainda, densidade de indivíduos, densidade de troncos e densidade por classe de diâmetro por hectare.

Para cálculo de área basal, foi utilizada a seguinte fórmula:

A.B. $=0,00007854 \times(D A P)^{2}$

Onde: $A B$ é a área basal em $\mathrm{m}^{2}$ e $\mathrm{DAP}$ o diâmetro à altura do peito, medido em centímetros.

Vale destacar que área basal do bosque é a soma das áreas basais de todos os troncos medidos por unidade de área. A área total da parcela (em $\mathrm{m}^{2}$ ) é convertida em 1 hectare (ha). Esta medida é um ótimo índice do grau de desenvolvimento estrutural do bosque, pois está relacionada ao volume de madeira e biomassa, assim como indicadora de estresse, neste caso refletindo nos valores de área basal morta.

Os dados obtidos com a análise estrutural permitiram a construção de gráficos e tabelas, com a finalidade de identificar possíveis diferenças entre as parcelas, caracterizando assim o bosque de mangue.

\section{RESULTADOS}

\section{Salinidade}

O gráfico abaixo (figura5) retrata o resultado desta análise. De um modo geral a salinidade variou de 14 a 41 . Aumentando à medida que vai entrando no bosque e se afastando do talude da estrada. O perfil $C$ apresentou resultado diferente dos demais, com queda abrupta da salinidade no final do perfil. Observação de campo indica que este fato pode ter ocorrido devido à pequena depressão próximo a um canal mareal, facilitando a diluição da salinidade devido ao maior aporte de água doce, ou ao acumule desta após a precipitação.

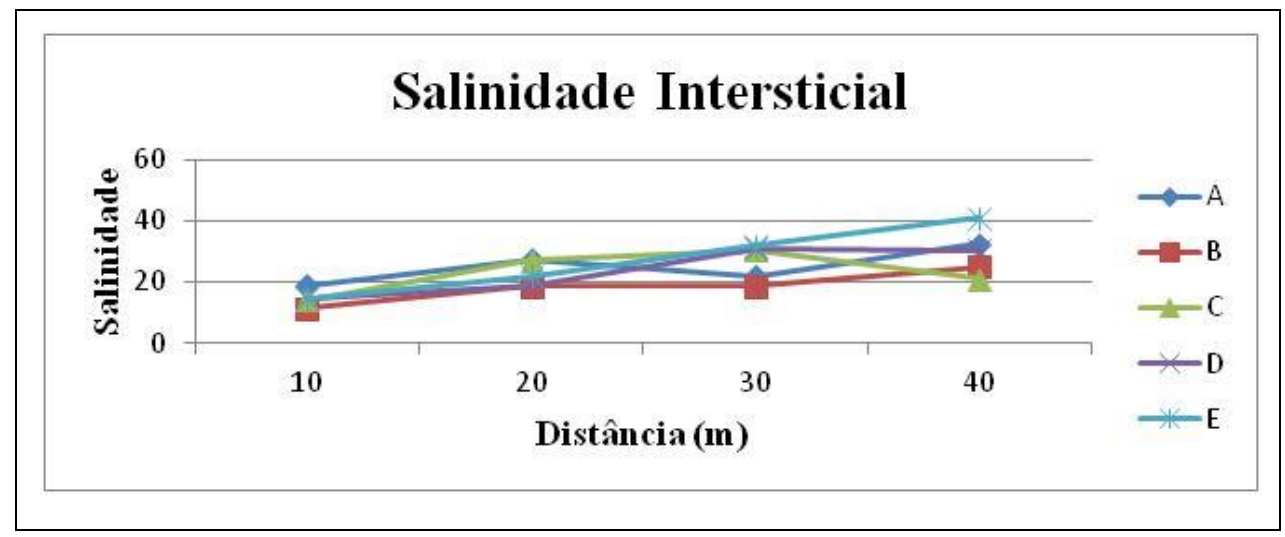

Figura 5 - Salinidade intersticial ao longo dos perfis A, B, C, D e E. 
ALMEIDA, V. C. et al. Caracterização estrutural do manguezal do rio Tabatinga, Suape, Pernambuco, Brasil.

\section{Caracterização Estrutural do Bosque de Mangue}

Foram identificadas duas espécies de mangue, Laguncularia racemosa e Avicennia schaueriana, segundo Schaeffer-Novellie e Cintron (1986).

A relação tronco/indivíduo é uma importante ferramenta que permite avaliar o grau de desenvolvimento do bosque. Quando esta relação fornece valores próximos ou igual a 1, pode indicar bosque desenvolvido.

A figura 6 mostra que a relação tron/ind variou de 1 (parcela A4) a 2parcela C2, representando bosque bem desenvolvido. Pode-se notar que não houve grande variação entre as parcelas.

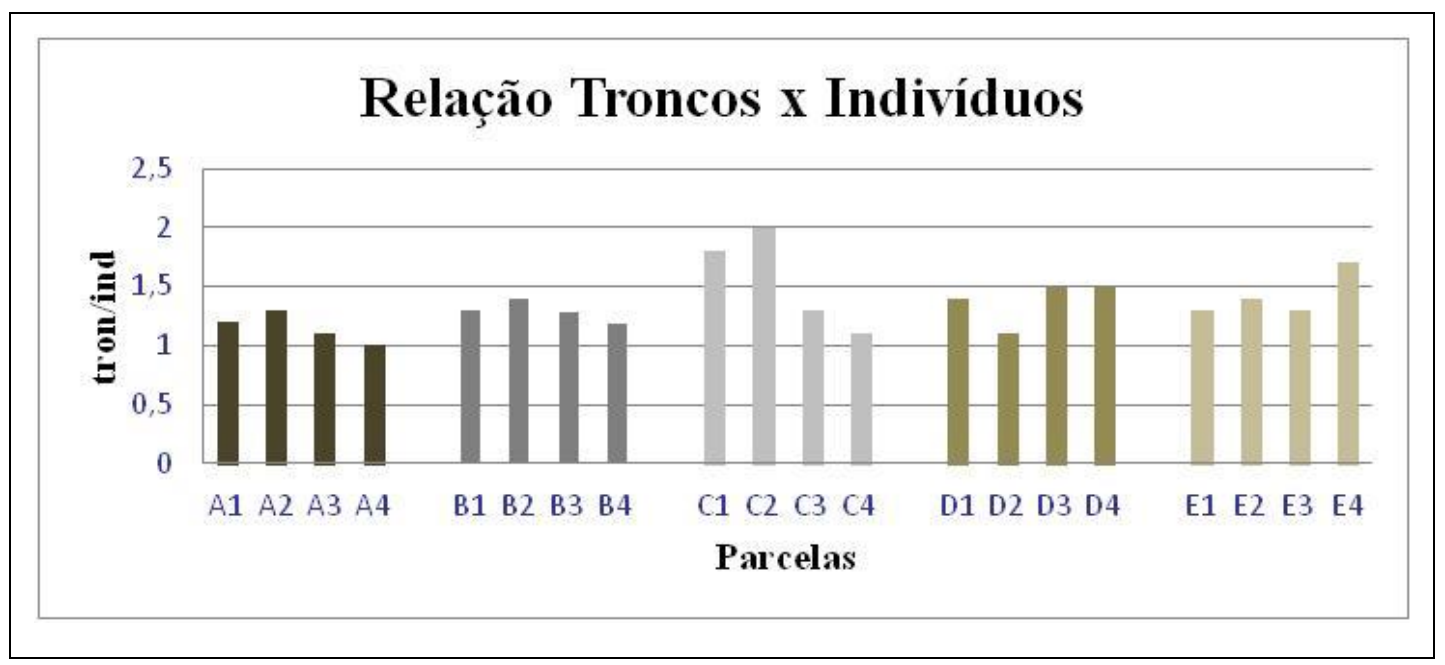

Figura 6 - Relação Tronco/Indivíduo nas parcelas dos perfis A, B, C, D e E.

A densidade de trocos total variou de 24.427 (B4) a 3.100 troncos/ha (E1) (Figura 7).Destaca-se as parcelas do perfil $C$ por apresentar menor densidade de troncos mortos, com A1 e C2 apresentando poucos troncos mortos. A parcela E1 foi a que apresentou a maior densidade de troncos mortos entre as parcelas, com mais de $90 \%$ da parcela. A densidade de troncos mortos foi bastante expressiva também nos perfis $D$ e $E$, como pode ser observado na figura abaixo.

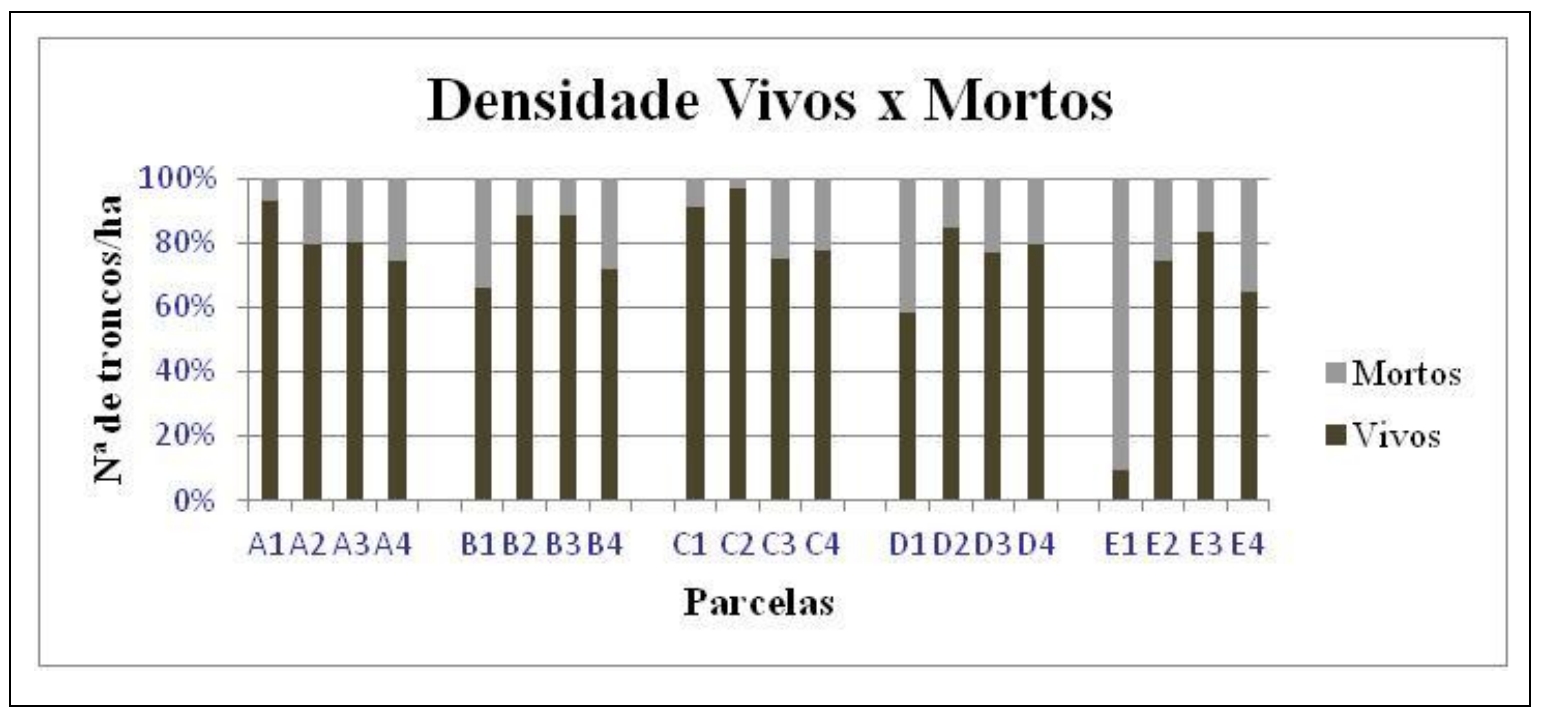

Figura 7 - Densidade relativa de troncos vivos e mortos nos perfis A, B, C, D e E.

No figura 8 pode-se notar um elevado número de troncos na classe de diâmetro $<2,5$, especialmente nos perfis $B$ e $D$, destacando a parcela $D 2$, representado mais de $80 \%$ da parcela. Por outro lado. O perfil C não apresentou elevados valores de troncos nesta classe, 
ALMEIDA, V. C. et al. Caracterização estrutural do manguezal do rio Tabatinga, Suape, Pernambuco, Brasil.

assim como o perfil $\mathrm{E}$, que representou o menor valor de densidade de troncos $<2,5$ na parcela E1,com $1 \%$ do total. O perfil Amostrou-se intermediário com densidade de troncos $\geq 2,5$ expressiva. Destaca-se a parcela A4 por representar o maior valor, aproximadamente $70 \%$ de classe diamétrica superior a 10 . Da mesma forma, para densidade na classe $\geq 10$, as parcelas C2 e E1 apresentaram percentagens altascom 25 e 30\%, respctivamente.

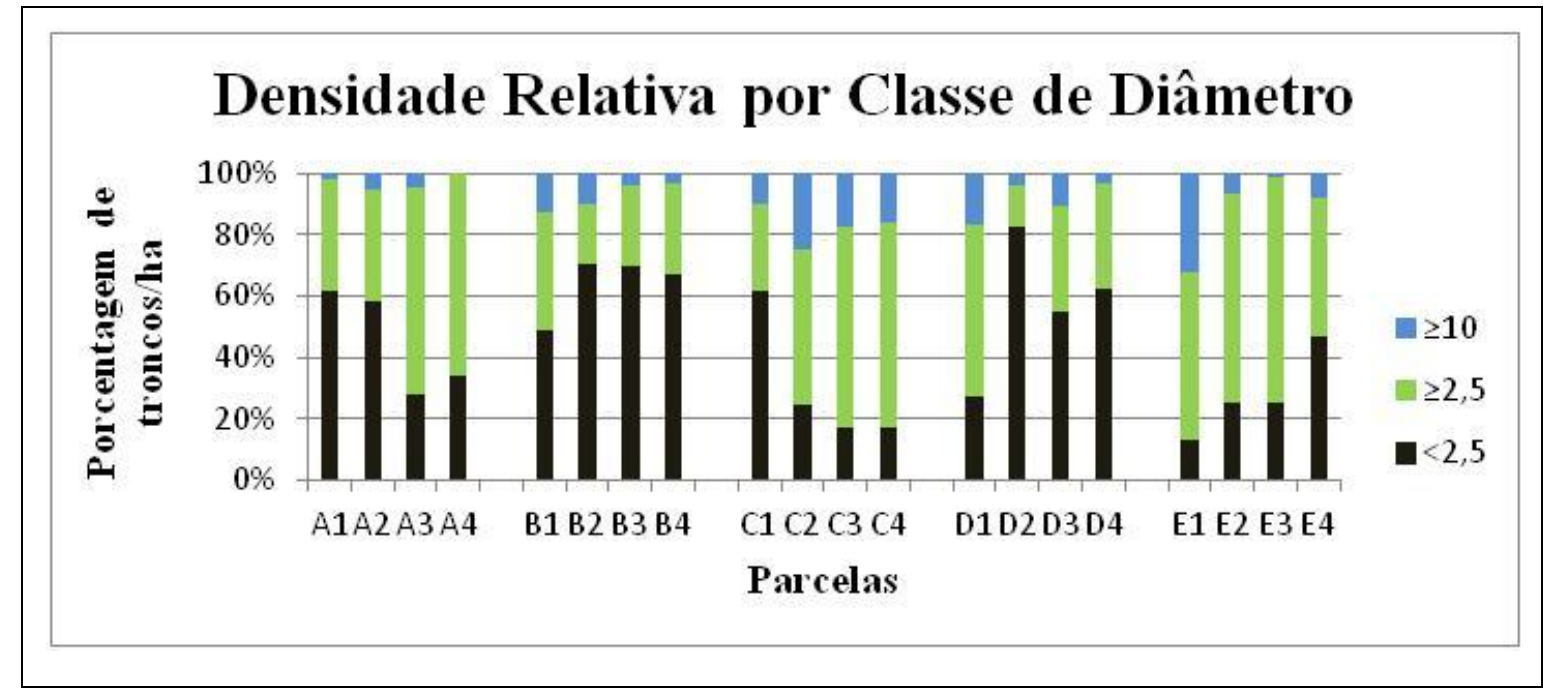

Figura 8 - Densidade relativa detroncos por classe diametrica, nos perfis A, B, C, D e E.

Os resultados obtidos das alturas médias estão estampados na figura 9 , onde as alturas variaram de $8,55 \pm 2,32$ em C3 e 3,57 $\pm 2,35 \mathrm{~m}$ em B3. O perfil C apresentou os maiores valores de altura média. Os perfis $A$ e $E$ tiveram pouca variação e o perfil $D$ teve uma tendência de crescimento à medida que adentra no bosque.

Quanto a altura do dossel (Figura 10) o maior valor foi em C1 com 12,85m e menor em B1 com 7,11m. De um modo geral a altura do dossel pouco variou. Mostrando se tratar de um bosque uniforme.

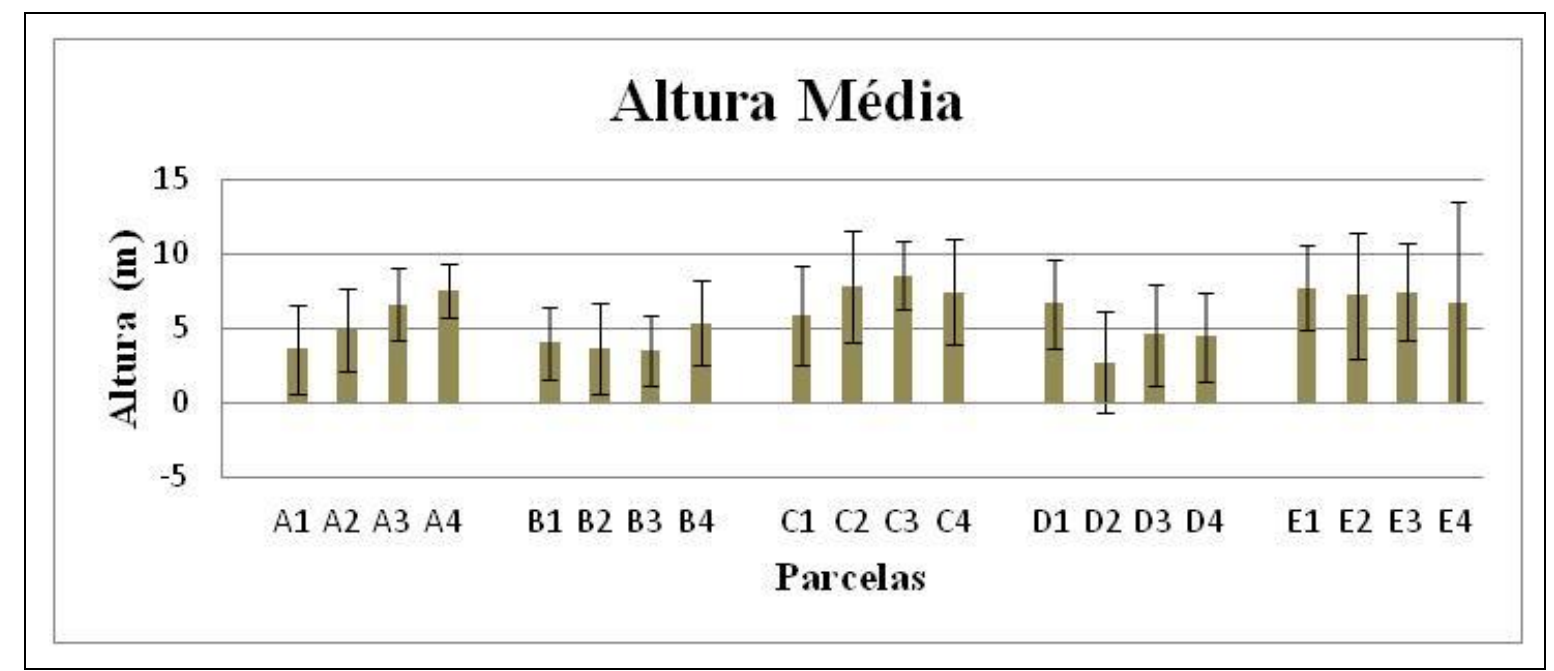

Figura 9 - Altura total média das parcelas ao longo dos perfis A, B, C, D e E. 


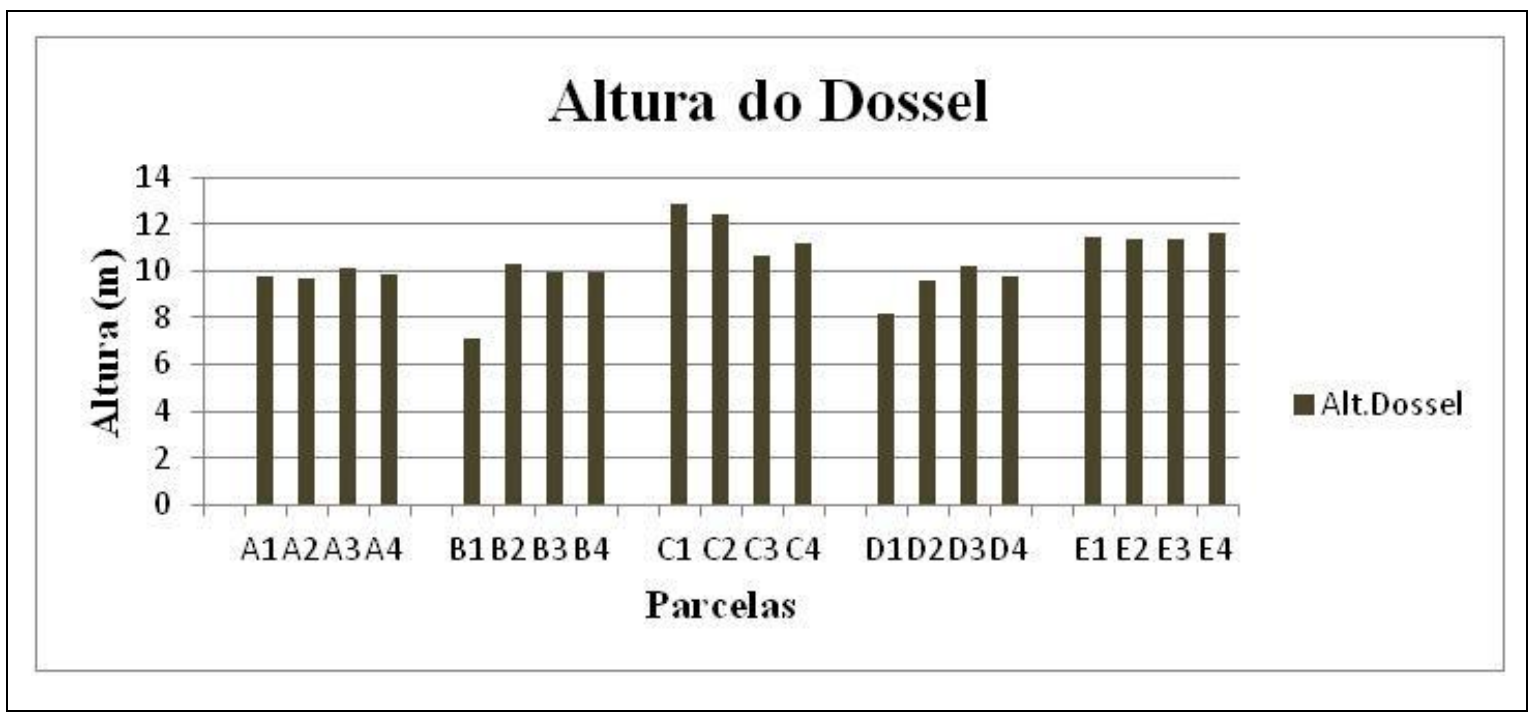

Figura 10 - Altura média do dossel ao longo dos perfis A, B, C, D e E.

A área basal total variou de 11,17 a $42,35 \mathrm{~m}^{2} / \mathrm{ha}$, ambos no perfil B (figura 11 ). O perfil E possui pouca diferença entre as parcelas.

Os valores de área basal $\geq 10$ variaram de 31,26 (B2)a $0,0 \mathrm{~m} 2 /$ ha (A4). Para classe $\geq 2,5$ variaram de 24,80 (E3) a $5,47 \mathrm{~m} 2 /$ ha (E1), e para a classe $<2,5$ variaram de 5,87 (D2) a 0,11 $\mathrm{m} 2 /$ ha em C3 e E1 (Figura 11). As parcelas B2, C2 e E1 possuem as maiores áreas basais com troncos maiores que $10 \mathrm{~cm}$. Enquanto que as parcelas A1, A2, A3 e E3 são as que apresentam menor contribuição de troncos maiores que $10 \mathrm{~cm}$.

Classes diamétricas inferiores não dominaram as parcelas estudadas, sendo D2 a maior expressiva em contribuição em área basal $<2,5 \mathrm{~cm}$.

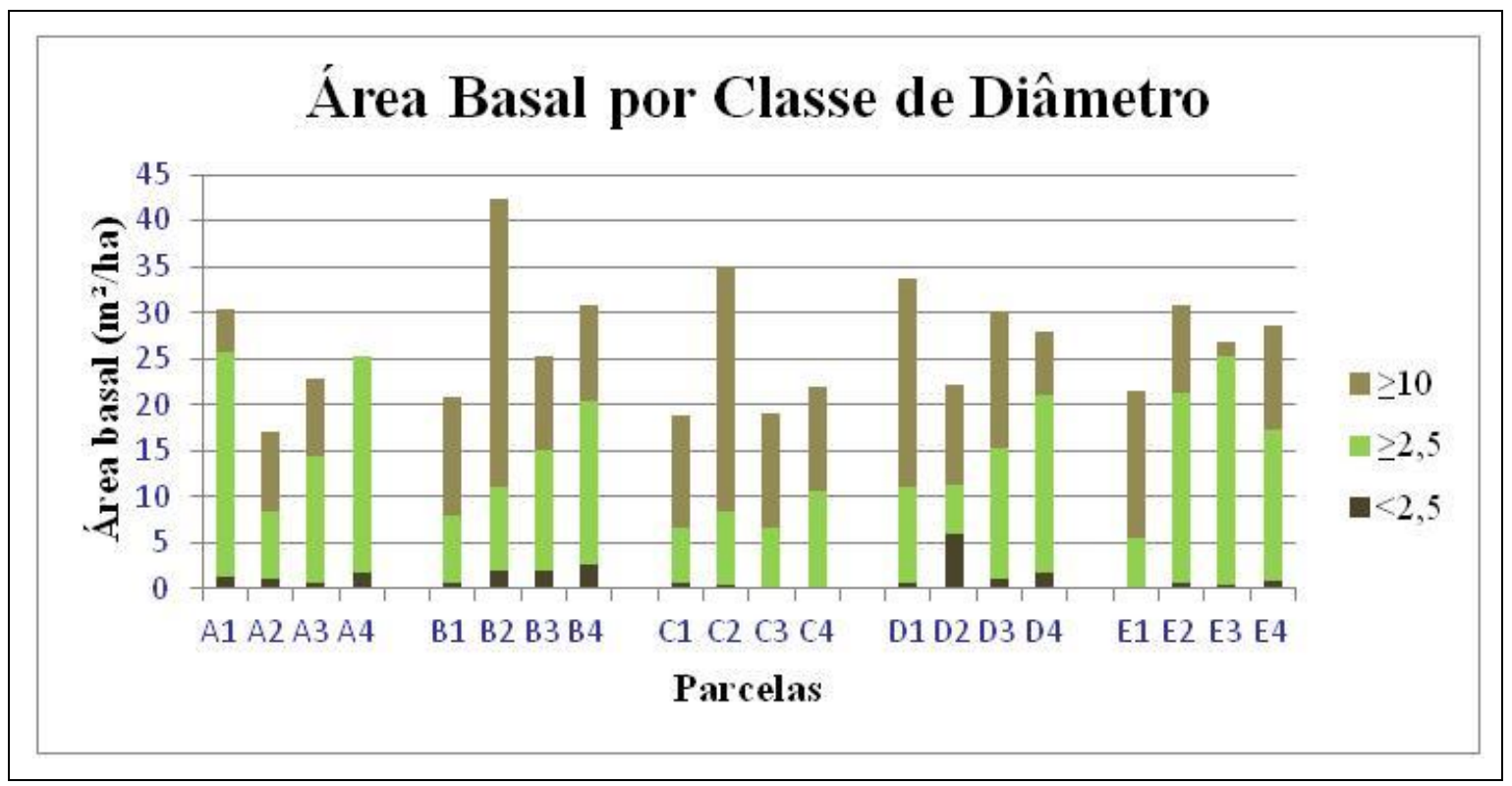

Figura 11 - Área basal por classe de diâmetrolongo dos perfis A, B, C, D e E.

A espécie dominante é a Laguncularia racemosa que ocorreu em $100 \%$ das parcelas. Nas parcelas do transecto $A$ destacam-se a pouca contribuição de troncos vivos para área basal total, mostrando-se um trecho sadio do bosque. Em contra partida, a parcela E1 apresentou o menor valor de área basal viva, com 3,81 m²/ha, cerca de $20 \%$ do total (Figura 12).

Avicennia schaueriana teve sua maior contribuição na parcela E4, com apenas, $7,3 \mathrm{~m}^{2} / \mathrm{ha}$ do total, correspondendo um pouco mais que $20 \%$. 


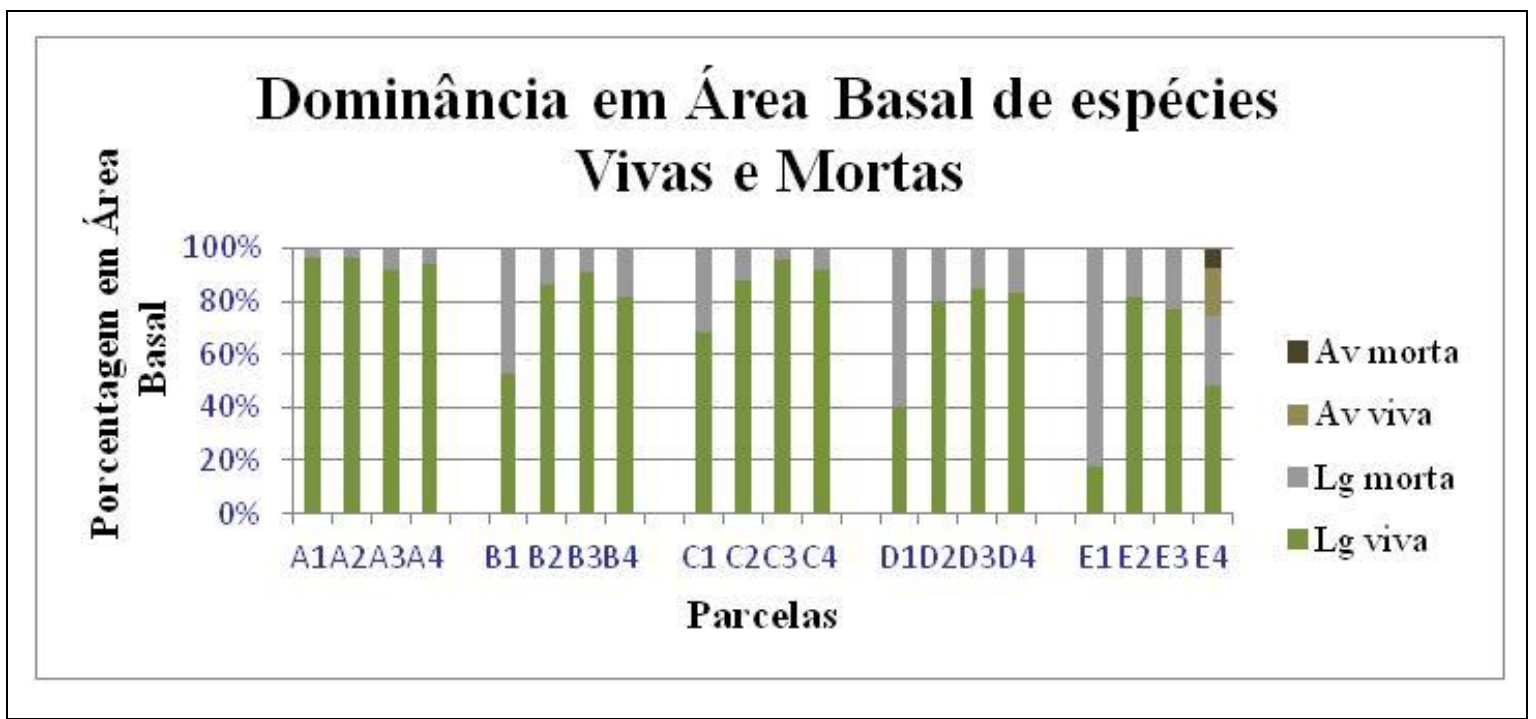

Figura 12: Dominância em área basal viva e morta dos perfis $A, B, C, D$ e $E$.

\section{DISCUSSÃO}

Nos manguezais de Suape são encontradas as seguintes espécies arbóreas típicas: R.mangle, L. racemosa, A. schauerianna e A. germinans. Há ainda a ocorrência da espécie Conocarpus erecta (mangue-de-botão), apontada como espécie de transição com a terra-firme (SOUZA E SAMPAIO, 2001).

A espécie $R$. mangle é comumente encontrada na franja dos manguezais, em contato com o estuário, em áreas frequentemente inundadas pelas preamares, principalmente nas proximidades das desembocaduras, sendo gradualmente substituída pelas espécies Avicennia e/ou L. racemosa na porção mais interna do bosque (SOUZA E SAMPAIO, op cit).

O Bosque de mangue estudado apresenta características típicas que permite descrevê-la como pertencente ao tipo bacia. Desenvolve-se nas áreas mais internas, atrás dos bosques de franja, a renovação da água é mais lenta, e ocorre ausência de fortes gradientes horizontais (SCHAEFFER-NOVELLI et al. 2000). Além disso, deve ser considerado monoespecífico, onde L. racemosa é dominante em todas as parcelas, com raríssima contribuição de $A$. Schaueriana.

O Gênero Laguncularia, encontra-se em costas de baixa salinidade e ao longo de canais de água salobra. Encontram-se também, nos bordos de praias arenosas de costas de baixa energia. Tolera salinidade superiores à 60 , mas aparenta competir mais efetivamente em áreas de baixa salinidade, devido a sua capacidade de excretar o excesso de sais pelas folhas(SCHAEFFER-NOVELLI e CINTRÓN, 1986.).

Nascimento-Filho (2007), em estudos desenvolvidos em áreas preservadas no rio Ariquindá (Tamandaré, PE), constatou que L. racemosa era a espécie que dominava o bosque de bacia estudado. O mesmo ocorrendo nos estudos de Cunha-Lingnon et al. (1999) e Coelho-Jr (1998) para os manguezais de Cananéia (São Paulo).

O bosque de mangue do rio Tabatinga apresentou área basal total parcelas com valores entre 11,17 e $42,35 \mathrm{~m}^{2} / \mathrm{ha}$. Essa diferença entre o desenvolvimento estrutural foi registrado por Souza e Sampaio (2001), nos manguezais de Suape, onde os autores encontraram bosques com 12,7 a $60,8 \mathrm{~m}^{2} /$ ha. Já Nascimento-Filho (2007), o bosque monoespecífico de $L$. racemosa atingiu $19,06 \mathrm{~m}^{2} / \mathrm{ha}$.

Foram realizados diversos trabalhos quanto à caracterização estrutural dos bosques de mangue. Silva et al. (2005),em estudo realizado no Espírito Santo, encontrou área basal variando entre 7,21 a $31,1 \mathrm{~m}^{2} / \mathrm{ha}$. Já no trabalho de Meireles et al. (2003) a área basal variou entre 12,7 a $60,8 \mathrm{~m}^{2} / \mathrm{ha}$. Ambos estudos reconheceram os bosques como bem desenvolvidos.

Os valores de área basal por classe diamêtrica ratificam a afirmação de que o bosque do rio Tabatinga é bem desenvolvido. É possível observar uma grande contribuição de troncos 
ALMEIDA, V. C. et al. Caracterização estrutural do manguezal do rio Tabatinga, Suape, Pernambuco, Brasil.

acima de $10 \mathrm{~cm}$ de diâmetro. Petri et al. (2011), estudando os manguezais do rio Benevente (ES), observaram a grande contribuição em área basal na classe diamétrica $\geq 10 \mathrm{~cm}$, que indicou um elevado desenvolvimento estrutural.

A altura é outra variável importante nesta análise. Nos manguezais nordestinos, os trabalhos apontam para altura média valores como, 12 a $28 \mathrm{~m}$ no Piauí (Deus et al.,2003),e 2,58 a 7,14 m em Cururipe na Bahia (Martins et al., 2011). Para Pernambuco, Nascimento-Filho (2007) encontrou altura de 0,4 (em bosques de bacia áreas hipersalinos) a 8,9m (nas franjas), e Souza e Sampaio, (2001) bosques de mangue entre 6,7 a $18 \mathrm{~m}$ na mesma região do presente estudo.

Observa-se que existe uma forte discrepância nos valores de densidade nos diversos trabalhos analisados no Brasil. Bernini e Rezende (2004), no estuário do rio Paraíba do Sul - RJ, onde a densidade variou de 1.920 a 3.400 troncos/ha. Souza e Sampaio (op cit) encontrou densidade entre 917 e 5.683 troncos/ha. E Nascimento-Filho (op cit) densidade variando entre 1.152 a 14.534 troncos/ha. Outro estudo que levou em consideração a densidade de troncos foi o de Medeiros (1996) no rio Paripe (PE), com 3.487 troncos/ha. Afirma a autora que este mangue não é jovem, considerando-se as árvores remanescentes de porte mais desenvolvido.

A densidade total de troncos do rio Tabatinga é relativamente alta se comparada com os trabalhos citados, retratando que apesar do bosque apresentar um bom desenvolvimento estrutural, existe sinal de stress em algumas parcelas estudadas e que levaram a recomposição do bosque, como pode ser observado na parcela D2. Nas demais parcelas a densidade foi menor, e com uma relação tronco/indivíduo pequena, confirmando a hipótese levantada, de se tratar de um bosque bem desenvolvido para a região.

Observou-se a presença de tensor na área, relacionado ao assoreamento em decorrência da erosão do talude da duplicação da Rodovia TDR-Norte, de acesso ao porto. A resposta do manguezal foi direta à presença do tensor, chegando à 6.856 troncos mortos/ha, como pode ser observado nas parcelas D1 e E1, ao lado do talude (Figura 13).

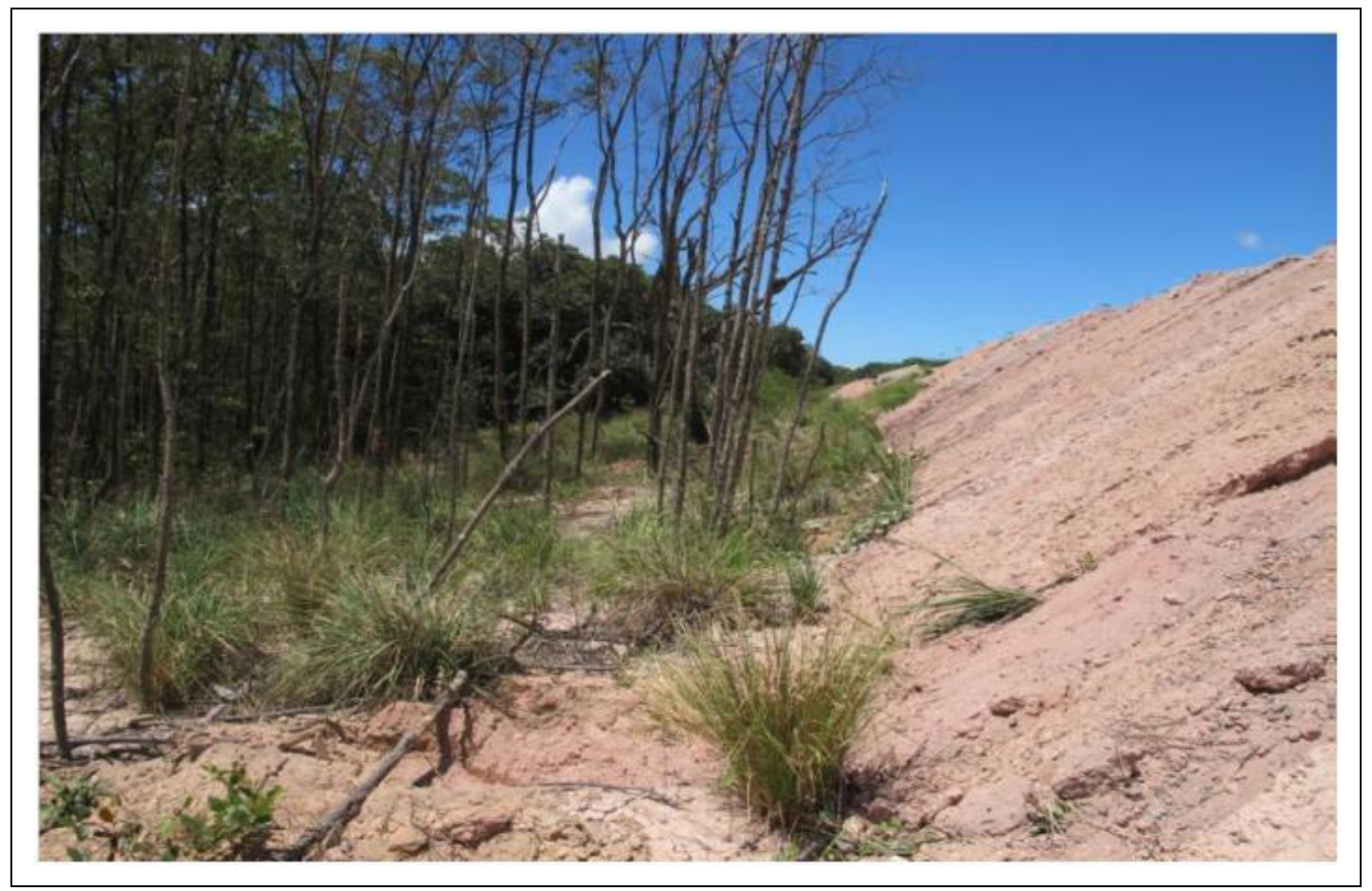

Figura 13: Detalhe do talude da duplicação da rodovia TDR-Norte.

Odum e Johannes (1975) após analisarem as respostas dos manguezais a stress, concluíram que os manguezais são muito sensíveis as trocas gasosas entre raízes e sedimento, portanto os tensores que interferissem nesses processos seriam os mais prejudiciais aos manguezais. 
ALMEIDA, V. C. et al. Caracterização estrutural do manguezal do rio Tabatinga, Suape, Pernambuco, Brasil.

L. racemosa caracteriza-se por conter um sistema radicular superficial estendidas horizontalmente. A partir destas raízes horizontais, desenvolve-se uma sequencia de raízes verticais pneumatóforos. Este tipo de raíz apresentam tecidos apropriados para facilitar a ventilação em solos inundados e com baixos teores de oxigênio, como os manguezais (JIMENEZ, 1985). Portanto, sufocamento das raízes pode levar a morte desta espécie, como observado nas parcelas D1 e E1.

Menghini (2008), analisando as ações dos tensores sobre os manguezais da Ilha de Barnabé, como queimadas, alterações hidrológicas, efluentes industriais, esgotos urbanos e outros oriundos das atividades portuárias, descreveu o comprometimento da qualidade dos manguezais, com interferências no desenvolvimento estrutural dos bosques de mangue e na sua capacidade de recomposição natural.

Observações in situ no manguezal do rio Tabatinga revelam que as primeiras parcelas estudadas têm sofrido forte ação de sedimentação, causado pela erosão e lixiviamento do solo do talude da rodovia TDR-Norte. Este fato pode ser o responsável pelos valores elevados de troncos mortos nas primeiras parcelas dos transectos, como descrito anteriormente.

O assoreamento observado pode estar interferindo na penetração das marés nestas áreas, ocasionando a morte das árvores. As marés constituem umas das energias subsidiárias mais importantes que incidem sobre as áreas de manguezais. A amplitude de maré determina a renovação das águas intersticiais e superficiais, levando consigo certa quantidade de oxigênio. Essa renovação tem papel importante no transporte, fixação e seleção de propágulos, bem como no transporte de matéria orgânica para as regiões adjacentes (SCHAEFFER-NOVELLI, 1995).

A parcela D2 se destacou, por apresentar valores de densidade de troncos vivo bastante representativo, principalmente na classe de diâmetro $<2,5$. Podemos inferir que a alta densidade de jovens é um sinal inequívoco ao processo de regeneração natural, em áreas que recebem ainda as preamares de sizígia.

Como muitas florestas, os manguezais são dinâmicos, possuem crescimento contínuo e constantemente se restabelecem e se renovam. Difere das florestas terrestres, principalmente, pelas adaptações requerentes a sobrevivência no ambiente do entremarés. Tais adaptações fazem com que o ecossistema manguezal seja apto a ocupar, dominar e se estabilizar nestes ambientes com severas condições hidrológicas e físico-químicas, sendo essencial desta forma a presença de processos regenerativos adaptáveis, progressivos e principalmente eficientes neste ecossistema (DUKE, 2001).

Menghini et al (2011) notaram nos manguezais da Baixada Santista (SP), a ocorrência de regeneração natural em clareiras que ocupam os intervalos do dossel devido à morte das árvores adultas.

Ainda que todos os perfis tivessem as primeiras parcelas localizadas próximos ao talude da Rodovia TDR-Norte, nem todas as parcelas sofreram impacto. É o caso da parcela C1, com poucos indivíduos mortos. Numa análise direta, pode-se dizer que o assoreamento não afetou este trecho, em função de elevar muito pouco a cota do terreno, permitindo que as marés alcancem este trecho do manguezal.

A salinidade não foi um fator preponderante para a zonação e nem para o desenvolvimento estrutural do manguezal estudado. Outros fatores estão relacionados ao desenvolvimento estrutural do bosque de mangue do rio tabatinga, como quantidade de oxigênio disponível para as raízes e concentração de nutriente. Tais fatores são fatores importantes e regulam o funcionamento do ecossistema, quanto a estrutura e produtividade e são regulados, principalmente, pela frequência de inundação das marés, taxa de evaporação e aporte de água doce (pluvial e fluvial) (LUGO; SNEDAKER, 1974).

Nas zonas mais baixas, a salinidade é praticamente a mesma da água das marés, cerca de 35 ou abaixo desse valor em sistemas que atuam forte descarga fluvial. Em regiões áridas, topograficamente mais elevadas e com menor frequência de inundação, a salinidade é geralmente alta, podendo chegar a 90 (WELLS, 1982), limite de tolerância das espécies típicas 
ALMEIDA, V. C. et al. Caracterização estrutural do manguezal do rio Tabatinga, Suape, Pernambuco, Brasil.

de mangue. O contrário acontece em regiões com elevado índice pluviométricos, abundante drenagem terrestre e boa infiltração, levando essas zonas a valores relativamente baixos de salinidade (SEMENIUK, 1983).

Apesar da precipitação média no mês de coleta (setembro de 2013) ter sido baixa, em torno de $153 \mathrm{~mm}^{3}$ (APAC, 2014), quando comparado aos meses de junho e julho (338 e 402 $\mathrm{mm}^{3}$ ) (APAC op cit.), o gradiente formado parece estar relacionado a drenagem do talude da estrada. À medida que se afasta do talude os valores de salinidade aumentam.

\section{CONCLUSÕES}

1. A caracterização estrutural revelou a existência de duas espécies de mangue na área, $L$. racemosa e $A$. schaueriana, porém, a dominância da primeira espécie, descreve o bosque como monoespecífico.

2. Segundo as variáveis estruturais levantadas o bosque de mangue do rio Tabatinga é maduro e apresenta um bom desenvolvimento estrutural.

3. A espécie $L$ racemosa não é indicadora de áreas alteradas, como comumente é descrita, pois compõe, no presente estudo, bosque com elevada biomassa.

4. Os resultados apontam ainda a ocorrência de impacto relacionado à sedimentação sobre o substrato do manguezal, devido à elevada densidade de troncos mortos em algumas parcelas estudadas.

5. As variáveis estruturais são fortes ferramentas para análise do grau de desenvolvimento dos bosques de mangue, podendo ser utilizada ainda para identificação de tensores e para o monitoramento a médio e longo prazos dos processos de regeneração e sucessão ecológica.

\section{REFERÊNCIAS BIBLIOGRÁFICAS}

ANDRADE, G. O.; LINS, R. C. Os Climas do Nordeste. In: VASCONCELOS, S. J. As regiões naturais do Nordeste, o meio e a civilização. Recife, CONDEPE. p. 95- 8, 1971

APAC. Disponível em: < http://www.apac.pe.gov.br >. Acessado em: 01 de janeiro de 2014.

BALL, M. C. Patterns of secondary succession in a mangrove forest of southern Florida.

Oecologia (Berl), v. 44, p. 226-235, 1980

BERNINI, E; REZENDE, C. E. Estrutura da vegetação em florestas de mangue do estuário do rio Paraíba do Sul, Estado do Rio de Janeiro, Brasil. Acta bot. bras. v. 18, n. 3, p. 491-502, 2004

BERNINI, E.; REZENDE, C. E. Variação estrutural em florestas de mangue do estuário do rio Itabapoana, ES-RJ. Biotemas, 23(1), 49 a 60, 2010

CAVALCANTI, DB. Estudo Fitossociológico da Área do Estuário do Rio Tatuoca. Relatório Final. DB Cavalcanti - Consultoria Ambiental. Ipojuca, PE, Brasil. 75p. 2010.

CINTRÓN, G.; SCHAEFFER-NOVELLI, Y. Características y desarrollo structural de lós manglares de norte y sur America. Ciência Interamericana, v. 25, n. 1-4, p.4-15, 1985.

CINTRÓN, G.; SCHAEFFER-NOVELLI. Methods for studying mangrove structure, pp. 91-113. In: S. C. Snedaker; J. G. Snedaker (eds.) The mangrove ecosystem: Research methods, UNESCO, Bungay, United Kingdom, 251 p. 1984.

COELHO-JR, C. Manguezal, desenvolvimento estrutural da cobertura vegetal ao longo de gradientes de inundação - Cananéia, Estado de São Paulo, Brasil. Dissertação de Mestrado, IOUSP, 108p, 1998

COELHO-JR, C. Ecologia de manguezais: zonação e dinâmica da cobertura vegetal em gradientes ambientais, Cananéia, São Paulo, Brasil. Tese de doutorado. Instituto Oceanográfico da Universidade de São Paulo. 166p. 2003. 
ALMEIDA, V. C. et al. Caracterização estrutural do manguezal do rio Tabatinga, Suape, Pernambuco, Brasil.

CUNHA- LIGNON.M.; ALMEIDA, R. E COELHO-JR, C. Tipos fisiográficos de bosques de mangue de Cananéia, São Paulo, Brasil. Anais VII COLACMAR- Congresso Latino Americano sobre Ciência Del Mar. 17-21 de outubro. Universidade Nacional de Trujillo, Peru. 614-615p. 1999.

CUNHA-LIGNON, M. Dinâmica do manguezal no sistema de Cananéia-Iguape, estado de São Paulo-Brasil. Dissertação de Mestrado. Instituto Oceanográfico, Universidade de São Paulo, 105p. 2001.

CUNHA-LIGNON, M. Desenvolvimento espaço-temporal no sistema costeiro Cananéia-Iguape, São Paulo, Brasil. Tese de doutorado. Instituto Oceanográfico, Universidade de São Paulo, 2005

DEUS, M.D.S.M.D.; SAMPAIO, E.V.D.S.B.; RODRIGUE, S.M.C.B.S.; ANDRADE, V.C.D. Estrutura da vegetação lenhosa de três áreas de manguezal do Piauí com diferentes históricos de antropização. Brasil Florestal, no 78, 2003

DUKE, C. N. Gap creation and regeneration processes driving diversity and structure of mangrove ecosystems. Wetlands and Ecology Management, (9): 257-269, 2001

Giri C, Ochieng E, Tieszen LL, Zhu Z, Singh A, Loveland T, Masek J, Duke N. Status and distribution of mangrove forests of the world using earth observation Satellite data. Global Ecology and Biogeography 20: 154-159, 2010

GOOGLE Earth. Programa Google Earth. Olinda - PE, Brasil. 2012

HUTCHINGS, P.; SAENGER, P. Ecology of Mangroves. University of Queensi and Press.370p., 1987

JIMÉNEZ, J. A.; LUGO, A. E.; CINTRÓN, G. Tree motality in mangrove forests. Biotropica, 17(3): 177-185. 1985

LUGO, A. E.; SNEDAKER, S. C. The ecology of mangroves. Rev. Ecol. Syst.(5), 1974

MARTINS, P. T. A.; COUTO, E. C. G.; DELABIE, J. H. C. Fitossociologia e Estrutura Vegetal do Manguezal do Rio Cururupe, Ilhéus, Bahia, Brasil. Revista de Gestão Costeira Integrada. 7 p. 2011

MMA. Gerência de Biodiversidade Aquática e Recursos Pesqueiros (2010) Panorama da conservação dos ecossistemas costeiros e marinhos no Brasil (APL. Prates, MA Gonçalves, and MR Rosa, Ed.). MMA/SBF/GBA, Brasília

MEDEIROS, T. C. Produtividade e biomassa das espécies arbóreas do manguezal do estuário do rio Paripe, em Vila Velha, Itamaracá - PE. Dissertação de Mestrado. Recife: Universidade Federal Rural de Pernambuco, 1996.

MEIRELES, M.; SAMPAIO, E.; RODRIGUEZ,S.; ANDRADE,V. Estrutura da vegetação lenhosa de três áreas de manguezal do piauí com diferentes históricos de antropização, Acta Botanica Brasilica. p.21. 2003.

MENGHINI, R. P. Ecologia de Manguezais: Grau de Perturbação e Processos Regenerativos em Bosque de Mangue da Ilha Barnabé, Baixada Santista, São Paulo, Brasil. Dissertação de Mestrado - Instituto Oceanográfico, Universidade de São Paulo, São Paulo. 19 p. 2004.

MENGHINI, R. P. Dinâmica da recomposição natural em bosques de mangue impactados:Ilha Barnabé (Baixada Santista), SP, Brasil. Tese (Doutorado em Oceanografia). Universidade de São Paulo- SP, 2008.

MENGHINI, R. P.; COELHO-JR, C.; ROVAI, A.S.; CUNHA-LIGNON, M.; SCHAEFFER-NOVELLI, Y; CINTRÓN, G. Massive mortalityof mangrove forests in Southe ast Brazil (Baixada Santista, Stateof São Paulo) as a resulto fharboring activities. Journalof Coastal Research, Special Issue 64, ISSN 0749-0208, 2011.

NASCIMENTO FILHO, G. A. Desenvolvimento estrutural e padrão de zonação dos bosques de mangue do rio Ariquindá, Baía de Tamandaré, Pernambuco. Dissertação de Mestrado-

Universidade Federal de Pernambuco, Brasil. Recife. p. 82. 2007 
ALMEIDA, V. C. et al. Caracterização estrutural do manguezal do rio Tabatinga, Suape, Pernambuco, Brasil.

ODUM, W. E.; JOHANNES, R. E.The response of mangroves to man induced environmental stress. In: FERGUSON WOOD, E. J., JOHANNES, R. E.(eds) Tropical marine pollution. Elsevier, Amsterdam, p.52-62, 1975

PETRI, D. J. C.; BERNINI, E.; SOUZA, L. M. D; REZENDE, C. E. Distribuição das espécies e estrutura do manguezal do rio Benevente, Anchieta, ES. Biota Neotrop.,vol. 11, no. 3, 2011

SCHAEFFER-NOVELLI, Y; CINTRÓN, G. Guia para estudo de áreas de manguezal, estrutura, função e flora. Caribbean Ecological Research. São Paulo, 150p. + 3 apêndices. 1986.

SCHAEFFER-NOVELLI, Y.; PERIA, L. C. S.; MENEZES, G. V.; GRASSO, M.; SOARES, M. G. L.; TOGNELLA, M. M. P. Manguezais Brasileiros, Caravelas Estado da Bahia. Anais do III

Simpósio de Ecossistemas da Costa Brasileira. Pub. ACIESP, 87 (1): 324-332. 1994.

SCHAEFFER-NOVELLI, Y., Manguezal: Ecossistema entre a Terra e o Mar. Caribbean

Ecological Research, São Paulo, 64 p. 1995

SCHAEFFER-NOVELLI, Y.; CINTRON-MOLERO, G.; SOARES, M. L. G. e DE-ROSA, M. T. Brasilian Mangroves. Aquat. Ecossis. Healt. AndManag. 3 (2000) 561-570. 2000

SCHAEFFER-NOVELLI, Y. Manguezal: ecossistema que ultrapassa suas próprias fronteiras. In: Congresso Nacional de Botânica, 53., 2002, Recife, p. 34-37. 2002

SEMENIUK, V. Mangrove distribuction in the northwesters Australia in relationship to regional and freshwater drainage. Vegetatio (53): 11-31. 1983

SILVA, M. A. B.; BERNINI, E.; CARMO, T. M. S. Características Estruturais de Bosques de Mangue do Estuário do Rio São Mateus, ES, Brasil. Acta Botânica Brasilica. 19(3): 465-471. 2005

SOARES, M. L. G.. Estrutura vegetal e grau de perturbação dos manguezais da Lagoa da Tijuca, Rio de Janeiro, RJ, Brasil. Rev. Bras. Biol., São Carlos, v.59, n. 3, 1999

SOUZA, M. M. A.; SAMPAIO, E. V. S. B. Variação Temporal da Estrutura dos Bosques de Mangue de Suape - PE após a Construção do Porto. Acta Botânica Brasilica. 15(1): 1- 12. 2001

SUAPE. Estudo fitossociológico da área do estuário do rio Tatuoca. Contrato no 088/2010. DB Cavalcanti - Consultoria Ambiental. Ipojuca, Novembro de 2010. 75p + anexos. 2010

WELLS, A. G. Mangrove vegetation of northern Australia. In: COUGH, B.F. (ed.). Mangrove ecosystem in Australia structure, function and management. University Press. p. 57-78. 1982 